\title{
The Global Kidney Health Atlas: Burden and Opportunities to Improve Kidney Health Worldwide
}

\author{
Joyita Bharati ${ }^{a}$ Vivek Jhab, c, d Adeera Levin ${ }^{\mathrm{e}}$ \\ aDepartment of Nephrology, Postgraduate Institute of Medical Education and Research, Chandigarh, India; \\ ${ }^{b}$ George Institute for Global Health, UNSW, New Delhi, India; 'School of Public Health, Imperial College, London, UK; \\ dPrasanna School of Public Health, Manipal Academy of Higher Education, Manipal, India; 'Division of Nephrology, \\ Providence Health Care, University of British Columbia, Vancouver, BC, Canada
}

\section{Keywords \\ Chronic kidney disease - Global health - Burden of illness · \\ Clinical trials · Collaboration · Advocacy · Atlas · Care}

\begin{abstract}
CKD is a growing public health problem. The Global Kidney Health Atlas (GKHA) is an important initiative of the International Society of Nephrology. The GKHA aims to improve the understanding of inter- and intranational variability across the globe, focusing on capacity for kidney care delivery. The GKHA survey was launched in 2017 and then again in 2019, using the same core data, supplemented by information about dialysis access and conservative care. Based on a WHO framework of the 6 building blocks essential for health care, the GKHA assesses capacity in 6 domains: information systems, services delivery, workforce, financing, access to essential medicines, and leadership/governance. In addition, the GKHA assesses the capacity for research in all regions of the world, across all domains (basic, translational, clinical, and health system research). The results of the GKHA have informed policy and been used to enhance advocacy strategies in different regions. In addition, through documentation of the disparities within and between countries and regions, initiatives have been launched to foster change. Since
\end{abstract}

the first survey, there has been an increase in the number of countries which have registries to document the burden of CKD or dialysis. For many, information about the burden of disease is the first step toward addressing care delivery issues, including prevention, delay of progression, and access to services. Worldwide collaboration in the documentation of kidney health and disease is an important step toward the goal of ensuring equitable access to kidney health worldwide.

(C) 2021 The Author(s)

Published by S. Karger AG, Basel

\section{Introduction}

The burden of CKD is a growing public health problem, with identification of CKD as the cause of years of life lost increasing from \#25 worldwide in 1990 to \#16 in 2017 and current projections that CKD will be the 5th highest contributor to years of life lost by 2040 [1]. Quantitatively, approximately 850 Million people have some form of kidney disease worldwide [2], which is more than the population of Europe, and approximately double the number of people living with diabetes.

karger@karger.com www.karger.com/anm

Karger $\stackrel{\text { ' }}{5}$

GOPEN ACCESS
2021 The Author(s)

Published by S. Karger AG, Basel

This article is licensed under the Creative Commons AttributionNonCommercial-NoDerivatives 4.0 International License (CC BYNC-ND) (http://www.karger.com/Services/OpenAccessLicense) Usage and distribution for commercial purposes as well as any distribution of modified material requires written permission.
Vancouver BC V6Z 1Y6 (Canada)

ALevin@ providencehealth.bc.ca 
Table 1. Overview of activities

\begin{tabular}{lll}
\hline Bridging the gaps & Building capacity & Connecting communities \\
\hline ISN global kidney health summit & ISN academy & ISN world congress of nephrology \\
\hline Political advocacy & ISN journals & ISN frontiers meetings \\
\hline 2018 UN-high-level meeting on NCDs & ISN programs & ISN global kidney health summit \\
\hline Declaration of Istanbul on organ & Kidney care network & \\
trafficking and transplant tourism & Saving young lives \\
& ISN-ANIO India Committee & \\
& ISN mentorship program & \\
& Scientific writing course & \\
\hline
\end{tabular}

ISN, International Society of Nephrology; UN, United Nations; NCDs, noncommunicable diseases; ANIO, American Nephrologists of Indian Origin.

The etiologies of kidney disease differ by world region, by ethnicity, and are impacted by socioeconomic status, environmental, and fetal-maternal health [3]. CKDs are linked to several noncommunicable diseases (NCDs) such as diabetes, hypertension, and cardiovascular disease, and in some instances contribute to the development of those NCDs. In addition to the variability in prevalence and causes around the world, healthcare systems for CKD management also vary between and within countries [4-6]. Moreover, the role of healthcare systems, in the prevention, identification, and outcomes of those living with kidney diseases is of relevance. As identified by Liyange et al. [7], many patients around the world do not have access to kidney replacement therapies (KRTs; dialysis or transplantation) and thus will die because of their kidney disease. The authors estimated that between 27 and 53\% of the population who needs KRT receives it, leaving approximately $2.3-7.1$ million people, mostly in low and low-middle income countries, without access to KRT. This inequity is estimated to grow over time as wealth disparities widen $[8,9]$. Public health strategies to promote kidney health are predicated on awareness of the burden of the disease, which in turn would lead to the generation of strategies to develop interventions.

The generation of health policies is formulated based on data, using templates and principles from existing policies, and integrated within other health priorities. In most regions of the world, there is a dearth of health policy directed at CKD. Interestingly, the costs of treatments are not always highlighted to policy makers to inform decisions about investments. Identification of risk and early disease and prevention of progression of CKD and its attendant cardiovascular disease are more cost-effective than dialysis or transplantation. However, many societies "invest" in these later "end-stage" treatments instead of preventing the disease upstream [10-12]. There are often political pressures to develop dialysis units as life-saving treatments despite their huge costs and nonsustainability in the absence of strategic planning and regulation on quality control.

The International Society of Nephrology (ISN) is a large international professional organization whose vision is "a future where all people have equitable access to sustainable kidney health." In order to achieve this vision, the ISN attempts to bridge the gaps of knowledge, policy, and care, build capacity in human resources, knowledge, and sustainability, and connect communities through common goals, education, research, and advocacy activities. There are many activities which ISN has undertaken and developed in order to achieve this mission and vision. Table 1 outlines these in more detail, and further, information can be found on the ISN website (www.theisn. org). Within the context of research and improved understanding of CKD and its causes, consequences, and cures, there are several international collaborative research efforts facilitated by the ISN with its partners. ISN-ACT (Advancing Clinical Trials) aims to connect the global kidney clinical trial community to increase capacity and quality of trials answering important questions; iNET CKD (International Network of CKD Cohorts) has established a collaborative research network with individuallevel data and bio-samples to examine variation in outcomes and biological parameters around the world and to leverage that information to inform clinical trials as needed [13-15]. The Hydration for Kidney Health initiative (ISN-H4KH), a partnership between Danone and ISN,
Bharati/Jha/Levin 
has established research projects and supported investigators who are interested in improving the understanding of the role of hydration in specific environments and specific kidney disease populations. The i3C (International Consortium of CKD of unknown origin Collaborators) is examining best ways to collate the myriad of activities occurring to investigate CKD of unknown origin, which is a worldwide problem affecting disadvantaged field workers in multiple countries. While the etiology of this condition is likely multifactorial, there are some common stressors identified which include heat stress and dehydration. There is a recognized need for unbiased and strategic research agendas to improve the understanding and outcomes of people in these regions around the globe. Two publications describing the need for simple frameworks for definition, data collection, and sharing are important contributions to this field [16, 17].

Importantly, in the context of improving worldwide kidney health, there is a recognized need for integrated approaches which include research, education, mobilization, outreach, alliance building, and policy development. It is from this perspective that the strategy of generating the evidence to describe the current state of kidney care, policy, research, and education was developed. The Global Kidney Health Atlas (GKHA) publications, in 2017 and $2019[18,19]$, are important elements of the strategy. The purpose of the GKHA surveys was to gather information on the current state of readiness, capacity, and competence for the delivery of kidney care across countries and regions of the world. The findings provide evidence for formulating positions and policy, providing representation and visibility, and mobilizing the community to enable local actions to improve the understanding of, and ultimately the outcomes of, CKD.

\section{The Global Kidney Health Atlas}

The rationale for the GKHA initiative was to improve the understanding of the inter- and intranational variability across the globe with respect to capacity for kidney care delivery. The objectives of the GKHA were to assess kidney care on the 6 dimensions of Universal Health Coverage (UHC): health workforce, financing, health service delivery, accessibility to treatment, governance, and leadership, and health information systems. These 6 dimensions have been chosen because their presence enables the assessment of indicators of national capacity and structure of kidney care [20-22]. The 2017 and 2019 publications of GKHA were major undertakings for the worldwide nephrology community and yielded an impressive amount of information, which subsequently has been

The Global Kidney Health Atlas used in Global Kidney Health Policy Forum (Mexico City, Mexico 2017; Melbourne, Australia 2019), and regional and local efforts to improve situations in specific locations.

The main results of the GKHA survey are described in detail in the main and ancillary publications [18, 19,23]. The GKHA relies on mixed methodology to obtain the information: desk research including annual reports, annual registries and global observatory, systematic reviews, and scoping reviews, followed by formal electronic surveys targeted at each country/region, and using perspectives of physicians, charitable foundations, and administrators, where available. Remarkably, within a 16 month period (December 2017-April 2019), the major stakeholders were identified, surveys developed, vetted, and distributed, results obtained, collated, analyzed, and prepared for presentation and publication (see Fig. 1). The capacity and structure of kidney care across the globe were evaluated in terms of the 6 dimensions of health systems toward UHC.

1. Workforce: there are workforce shortages in nephrologists and allied healthcare professionals: nurses, vascular access specialists, radiologists, surgeons, dieticians, social workers, and pharmacists [24]. In addition to the lack of trained individuals, the capacity to train the next generation is also limited. Low-income countries have lesser number of nephrologists and least number of trainees, thus perpetuating the problem.

2. Governance and leadership: there were few countries or regions with national kidney strategies for CKD or acute kidney injury (AKI) despite the growing literature on the importance of each of these in the context of public health problems, and the link between them. Those with AKI are at risk for CKD, and those with CKD are at risk for AKI episodes, which in turn may exacerbate the trajectory of $\mathrm{CKD}$. In multiple regions around the world, poor sanitation, lack of access to clean water, and infections are all contributors to AKI and CKD. National government involvement in CKD care was reported in only $50 \%$ of all countries.

3. Financing: few countries have public funding for kidney care or proper surveillance or detection strategies $[25,26]$. The funding models for kidney care including KRT vary tremendously, and paradoxically, the publicly funded KRT dollar allotments are higher than similar allotments for nondialysis treatments. About 65 and $48 \%$ of all countries provide public funding for KRT and nondialysis CKD care, respectively. As expected, public funding was more in high-income 


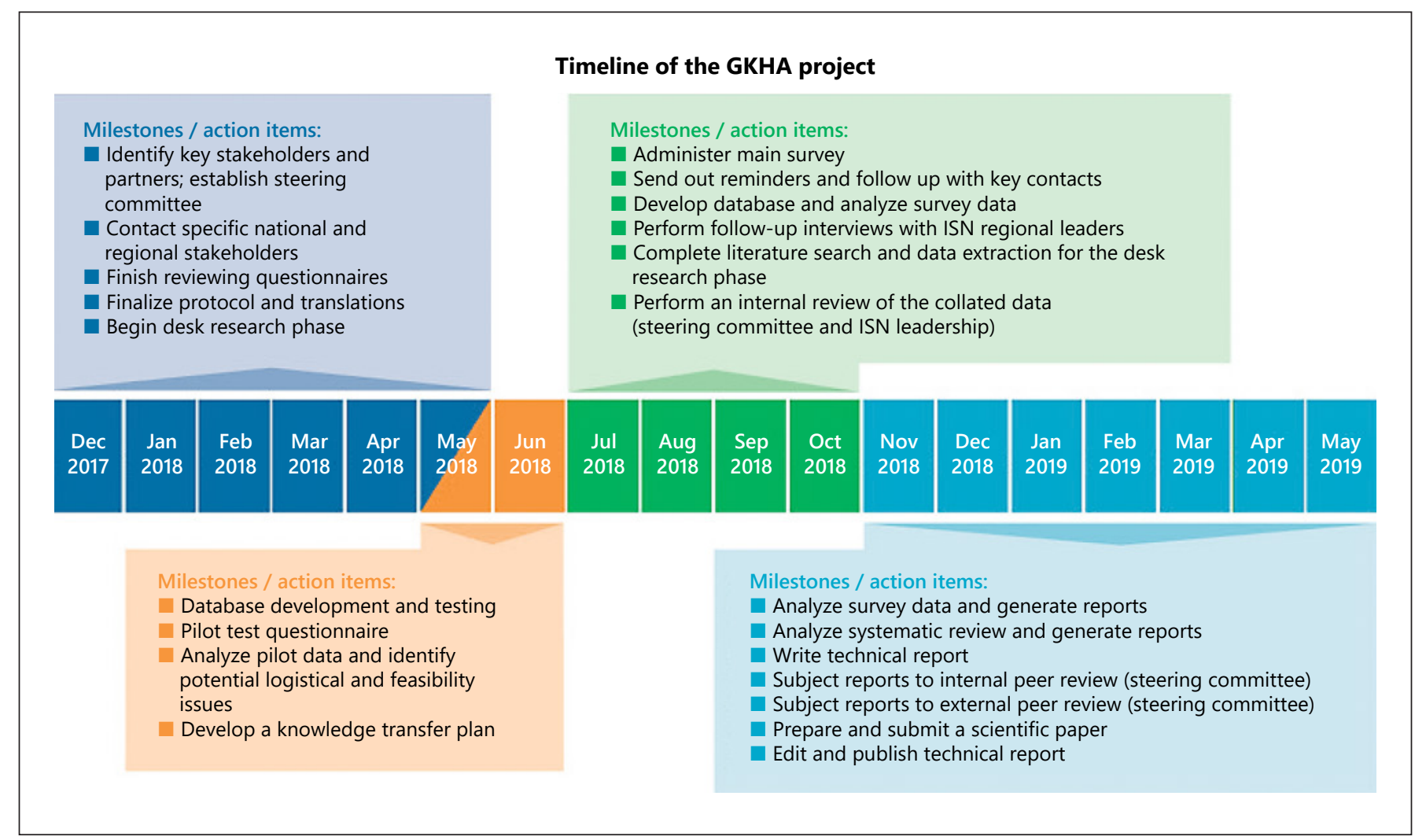

Fig. 1. Timeline of the GKHA project. ISN, International Society of Nephrology; GKHA, Global Kidney Health Atlas.

countries than in low-income countries. More funding is allocated for expensive dialysis or transplant treatments than for early identification, surveillance, and prevention. In addition, out-of-pocket expenses for treatment costs borne by patients are the highest in low and lower middle income countries. Patients on dialysis suffer economic hardships [27].

4. Healthcare information systems: registries for CKD and AKI are almost nonexistent (on a national level). While dialysis and transplant registries do exist, in many jurisdictions, these are not mandatory and are not even available in all higher income countries [28, 29]. About $66 \%$ of all countries had registries for dialysis with minimal representation of nondialysis $\mathrm{CKD}$ and AKI registries. Without objective data, the true burden of the condition is difficult to appreciate.

5. Accessibility of treatment: most (95\% in 2017 and $100 \%$ in 2019 survey) countries have hemodialysis facilities, and about three-fourths have facilities for transplantation and peritoneal dialysis (PD). However, these facilities were available to $>50 \%$ of the patient population in only $70 \%$ of these counties.
6. Health service delivery: the infrastructure for kidney care was reported to be "good" in $\sim 40 \%$ of the countries. These were frequently shown to be poor in lowincome countries. Laboratory support for CKD management was also noted to be poor in low-income countries.

In addition, the GKHA examined the capacity to conduct clinical trials and basic research in kidney disease [30]. Despite kidney disease disproportionately affecting low-income countries, and those of Asian, South Asian, Filipino, and black racial backgrounds, the ability to conduct research including people in those countries remains limited.

\section{Results}

The 2017 and 2019 GKHA were conducted using the same methodology and leveraging of the ISN Regional Board infrastructure (https://www.theisn.org/about-isn/ regions). The core surveys were the same, but the 2019 GKHA included a focus on end-stage kidney disease and 
palliative or conservative care, with additional questions to ascertain differences in availability versus accessibility of services, which was not possible with the 2017 survey structure. Changes were documented in the 2-year period between surveys [19]. The number of countries surveyed also increased in 2019.

In 4 countries (Bolivia, Egypt, Fiji, and Swaziland), PD, an effective home-based therapy, was offered in 2019 whereas it had not been available in 2017. However, in another 4 countries (Armenia, Kenya, Syria, and Uganda), the ability to offer PD services in 2017 was lost by 2019. The reasons for some of these changes are political, economic, or due to changes in human resources. Overall in $2019,80 \%$ of countries had the ability to offer PD, whereas in 2017 , only $76 \%$ could do so. The ability to offer transplantation was static worldwide, with only Tanzania reporting in 2019 that they were able to offer transplantation, whereas in 2017 they did not.

Of note, the number of registries for CKD and AKI appears to be increasing: from 8 to $7 \%$ of countries, respectively, in 2017, to 12 and $8 \%$ in 2019 . And more countries reported dialysis and transplant registries in 2019 than in 2017 (75/117 and 68/117 in 2017 vs. $101 / 154$ and 88/154 in 2019). We cannot comment on the accuracy or methods of the registries, only their reported presence or absence.

While this may not seem like a big change, the value of registries in appreciating the size of the problem, informing policy makers and healthcare providers, as well as the public, about CKD, AKI, and KRT cannot be overstated. These data are useful for advocacy, research, and healthcare system reform efforts, as articulated in the publication describing the roadmap for closing the gaps in care, policy, and research [31]. The GKHA has been showcased in publications and 2 global policy forums alongside the World Congresses of Nephrology at Mexico City (2017) and Melbourne (2019). Multiple organizations including healthcare professionals, government agencies, and researchers, can and have used the information to develop concrete plans to address specific issues. Given the ISN's role as a nonstate actor in official relations with the WHO, $\mathrm{CKD}$ is getting more recognition in the context of global NCD agenda, and data from the GKHA are helpful in those venues and activities.

\section{Summary}

For the first time, the GKHA has reported data on kidney care delivery across the globe in lines of the 6 dimensions of UHC. Health systems between and within coun- tries have been compared to highlight issues pertaining to different countries. The findings highlight substantial challenges that health systems of many countries face in closing the large gaps that currently exist in meeting the health needs of people with AKI and CKD around the world. Urgent issues include addressing the financial burden of dialysis therapy and advocating cost-effective alternatives (PD vs. hemodialysis, and investment in upstream surveillance and prevention); workforce strategies and the expenses of training, alternative care delivery models, simple metrics and quality indicators, health information systems and government policies, and advocacy particularly for "business case for care." Most importantly, the GKHA is an international demonstration of collaboration in the commitment to sustained and robust data collection. Information gathered within the framework of UHC tenants is very powerful and useful as an ongoing tool for comparison over time and within countries and regions.

\section{Conclusion}

The GKHA serves to identify opportunities and challenges in the care and delivery of health care to people living with kidney diseases. It represents a commitment of the global nephrology commitment to prioritize sustainable health care for people living with or at risk of kidney disease. The GKHA has provided evidence on which countries can formulate policies, and build strategic partnerships to address the global burden of kidney disease. While the GKHA identifies the important challenges relating to the current state of kidney care, it also provides opportunities for targeted intervention to address these challenges in a consultative, equitable, and resource-sensitive manner in different parts of the world. Finally, the GKHA provides an established platform that can be to monitor progress and make global comparisons, which complement the high-level disease burden data from initiatives such as the Global Burden of Disease Study.

\section{Acknowledgements}

The author thanks the GKHA core team Dr. A. Bello, Dr. M. Lunney, and Dr. D. Johnson and ISN staff members Sandrine Damster, Luisa Strani, and Jo-Ann Donner, who enabled the outstanding execution and dissemination of the GKHA. Furthermore, thank you to all the ISN Regional Board members, participants, and the general ISN membership in totality, for enabling the outstanding work (very briefly presented here) to be undertaken. 


\section{Statement of Ethics}

The project was approved by the University of Alberta Research Ethics Committee (protocol number PRO00063121). All individual participants provided written informed consent.

\section{Conflict of Interest Statement}

A. Levin and V. Jha received travel expenses and registration fees from Danone Research to attend the 2017 and 2019 Hydration for Health Scientific Conference.

\section{References}

1 Xie Y, Bowe B, Mokdad AH, Xian H, Yan Y, Li T, et al. Analysis of the Global Burden of Disease study highlights the global, regional, and national trends of chronic kidney disease epidemiology from 1990 to 2016 . Kidney Int. 2018;94(3):567-81.

2 [cited 2020 Feb 25]. Available from: https:// www.theis n.org/i m a ges / A S N PR_20180627_Final6.26.18Press_E.pdf.

3 Marmot M, Bell R. Social determinants and non-communicable diseases: time for integrated action. BMJ. 2019 Jan 28;364:1251.

4 Hsu CY, Lin F, Vittinghoff E, Shlipak MG. Racial differences in the progression from chronic renal insufficiency to end-stage renal disease in the United States. J Am Soc Nephrol. 2003;14(11):2902-7.

5 Barbour SJ, Schachter M, Er L, Djurdjev O, Levin A. A systematic review of ethnic differences in the rate of renal progression in CKD patients. Nephrol Dial Transplant. 2010; 25(8):2422-30.

6 Weldegiorgis M, Smith M, Herrington WG, Bankhead C, Woodward M. Socioeconomic disadvantage and the risk of advanced chronic kidney disease: results from a cohort study with 1.4 million participants. Nephrol Dial Transplant. 2020 Sep 1;35(9):1562-70.

7 Liyanage T, Ninomiya T, Jha V, Neal B, Patrice HM, Okpechi I, et al. Worldwide access to treatment for end-stage kidney disease: a systematic review. Lancet. 2015;385(9981): 1975-82.

8 Coresh J, Jafar TH. Disparities in worldwide treatment of kidney failure. Lancet. 2015; 385(9981):1926-8.

9 Crews DC, Bello AK, Saadi G. Burden, access, and disparities in kidney disease. Kidney Int. 2019;95(2):242-8.

10 Winkelmayer WC, Weinstein MC, Mittleman MA, Glynn RJ, Pliskin JS. Health economic evaluations: the special case of endstage renal disease treatment. Med Decis Making. 2002;22(5):417-30.

11 Manns BJ, Mendelssohn DC, Taub KJ. The economics of end-stage renal disease care in Canada: incentives and impact on delivery of care. Int J Health Care Finance Econ. 2007; $7(2-3): 149-69$

12 Honeycutt AA, Segel JE, Zhuo X, Hoerger TJ, Imai K, Williams D. Medical costs of CKD in the medicare population. J Am Soc Nephrol. 2013;24(9):1478-83.
13 Dienemann T, Fujii N, Orlandi P, Nessel L, Furth SL, Hoy WE, et al. International network of chronic kidney disease cohort studies (iNET-CKD): a global network of chronic kidney disease cohorts. BMC Nephrol. 2016; 17(1):121.

14 Orlandi PF, Huang J, Fukagawa M, Hoy W Jha $\mathrm{V}$, Oh $\mathrm{KH}$, et al. A collaborative, individual-level analysis compared longitudinal outcomes across the International Network of Chronic Kidney Disease (iNETCKD) cohorts. Kidney Int. 2019;96(5):1217-33.

15 Alencar de Pinho N, Levin A, Fukagawa M, Hoy WE, Pecoits-Filho R, Reichel H, et al. Considerable international variation exists in blood pressure control and antihypertensive prescription patterns in chronic kidney disease. Kidney Int. 2019;96(4):983-94.

16 Caplin B, Yang CW, Anand S, Levin A, Madero M, Saran R, et al. The International Society of Nephrology's International Consortium of Collaborators on Chronic Kidney Disease of Unknown Etiology: report of the working group on approaches to population-level detection strategies and recommendations for a minimum dataset. Kidney Int. 2019;95:4-10.

17 Anand S, Caplin B, Gonzalez-Quiroz M, Schensul SL, Bhalla V, Parada X, et al. Epidemiolgy, molecular, and genetic methodologies to evaluate causes of CKDu around the world: report of the Working Group from the ISN International Consortium of Collaborators on CKDu. Kidney Int. 2019;96(6):125460.

18 Bello AK, Levin A, Tonelli M, Okpechi IG, Feehally J, Harris D, et al. Assessment of global kidney health care status. JAMA. 2017; 317(18): 1864-81.

19 Bello AK, Levin A, Lunney M, Osman MA, Ye F, Ashuntantang GE, et al. Status of end stage kidney disease in countries and regions worldwide: international cross sectional survey. BMJ. 2019 Oct 31;367:15873.

20 World Health Organization. Monitoring the building blocks of health systems: a handbook of indicators and their measurement strategies. 2010. [cited 2020 Feb 25]. Available from: https://www.who.int/healthinfo/systems/WHO_MBHSS_2010_full_web.pdf.

21 World Health Organization. Assessing national capacity for the prevention and control of noncommunicable diseases: report of the 2015 global survey. 2016. [cited 2020 Feb 25]. Available from: https://apps.who.int/iris/bitstream/ handle/10665/246223/9789241565363-eng. pdf; jsessionid=A743BD3FC85AACD6C152D 790F3E83698? sequence $=1$.
22 Luyckx VA, Tonelli M, Stanifer JW. The global burden of kidney disease and the sustainable development goals. Bull World Health Organ. 2018;96(6):414-22D.

23 Bello AK, Johnson DW, Feehally J, Harris D, Jindal $\mathrm{K}$, Lunney $\mathrm{M}$, et al. Global kidney health atlas (GKHA): design and methods. Kidney Int Suppl (2011). 2017;7(2):145-53.

24 Osman MA, Alrukhaimi M, Ashuntantang GE, Bellorin-Font E, Benghanem Gharbi M, Braam B, et al. Global nephrology workforce: gaps and opportunities toward a sustainable kidney care system. Kidney Int Suppl (2011). 2018;8(2):52-63.

25 Bello AK, Alrukhaimi M, Ashuntantang GE, Bellorin-Font E, Benghanem Gharbi $M$, Braam B, et al. Global overview of health systems oversight and financing for kidney care. Kidney Int Suppl. 2018;8(2):41-51.

26 Luyckx VA, Smyth B, Harris DCH, PecoitsFilho R. Dialysis funding, eligibility, procurement, and protocols in low- and middle-income settings: results from the International Society of Nephrology collection survey. Kidney Int Suppl (2011). 2020;10(1):e10-8.

27 Manns B, McKenzie SQ, Au F, Gignac PM, Geller LI. The financial impact of advanced kidney disease on canada pension plan and private disability insurance costs. Can J Kidney Health Dis. 2017;4:2054358117703986.

28 Lunney M, Alrukhaimi M, Ashuntantang GE, Bello AK, Bellorin-Font E, Benghanem Gharbi $\mathrm{M}$, et al. Guidelines, policies, and barriers to kidney care: findings from a global survey. Kidney Int Suppl. 2018;8(2):30-40.

29 See EJ, Alrukhaimi M, Ashuntantang GE, Bello AK, Bellorin-Font E, Benghanem Gharbi $\mathrm{M}$, et al. Global coverage of health information systems for kidney disease: availability, challenges, and opportunities for development. Kidney Int Suppl (2011). 2018;8(2):7481.

30 Okpechi IG, Alrukhaimi M, Ashuntantang GE, Bellorin-Font E, Benghanem Gharbi M, Braam B, et al. Global capacity for clinical research in nephrology: a survey by the International Society of Nephrology. Kidney Int Suppl (2011). 2018;8(2):82-9.

31 Levin A, Tonelli M, Bonventre J, Coresh J, Donner JA, Fogo AB, et al. Global kidney health 2017 and beyond: a roadmap for closing gaps in care, research, and policy. Lancet. 2017;390(10105):1888-917. 